\title{
Management of Deep Sternal Wound Infection: Complete Sternal Osteomyelitis
}

\author{
Khaled Ebrahim Al-Ebrahim, FRCSC \\ Department of Surgery, King Abdulaziz University, Jeddah, Saudi Arabia
}

\section{ABSTRACT}

Deep sternal wound infection (DSWI) after cardiac surgery is a challenging complication that affects the outcome of surgery. The worst type of DSWI is mediastinitis and sternal osteomyelitis, which dramatically increase morbidity, mortality, and cost of care. This case report describes successful treatment of sternal osteomyelitis after open heart surgery with combined negative pressure wound therapy and rectus abdominis flap. This combination of negative pressure wound therapy with rectus abdominis flap in treating sternal osteomyelitis after open cardiac surgery is not well studied.

\section{INTRODUCTION}

The incidence of deep sternal wound infection (DSWI) after cardiac surgery ranges from $0.4 \%$ to $8 \%$ depending on multiple risk factors related to the patient, surgeon, and procedure [Farsky 2011; Cutrell 2016]. From 2005 to 2019, 30 cases of deep sternal wound infection were reported [Elassal 2020], and among them, 3 cases of complete sternal necrosis secondary to osteomyelitis were treated in our hospital with negative pressure wound therapy followed by rectus abdominis flap [Elassal 2020]. One of these cases is reported here.

\section{CASE REPORT}

A 68-year-old diabetic male presented with cough, fever, and purulent discharge 2 weeks after coronary bypass surgery. Culture showed coagulase-negative Staphylococcus. The lower sternum was unstable. The wound infection was assessed comprehensively by the cardiac surgery team and infection control. Computerized tomography (CT) scan imaging to assess the extent of bone damage and range of the infection showed sternal dehiscence and substernal collection. Deep sternal wound infection with sternal dehiscence was the diagnosis.

Appropriate antibiotics were started according to sensitivity, to be continued for $\geq 6$ weeks. Initial negative pressure wound therapy (NPWT) of $-125 \mathrm{mmHg}$ for 1 week was started. This was followed by surgical debridement and reinforced sternal

Received November 13, 2020; accepted March 13, 2020

Correspondence: Khaled E. Al-Ebrahim Department of Surgery, King Abdulaziz University Hospital, PO Box 80215, Jeddah 21589, Saudi Arabia; +6401000; fax:+6401238. (e-mail: dr.k.ebrabim@gmail.com). closure using pectoralis major fascia. Twelve days after the second procedure, the wound was discharging pus again with recurrent sternal dehiscence (Figure 1). Continuous NPWT was reapplied for 1 week. The second re-exploration revealed complete sternal necrosis. Total sternectomy and debridement of all residual necrotic tissue was done, followed by

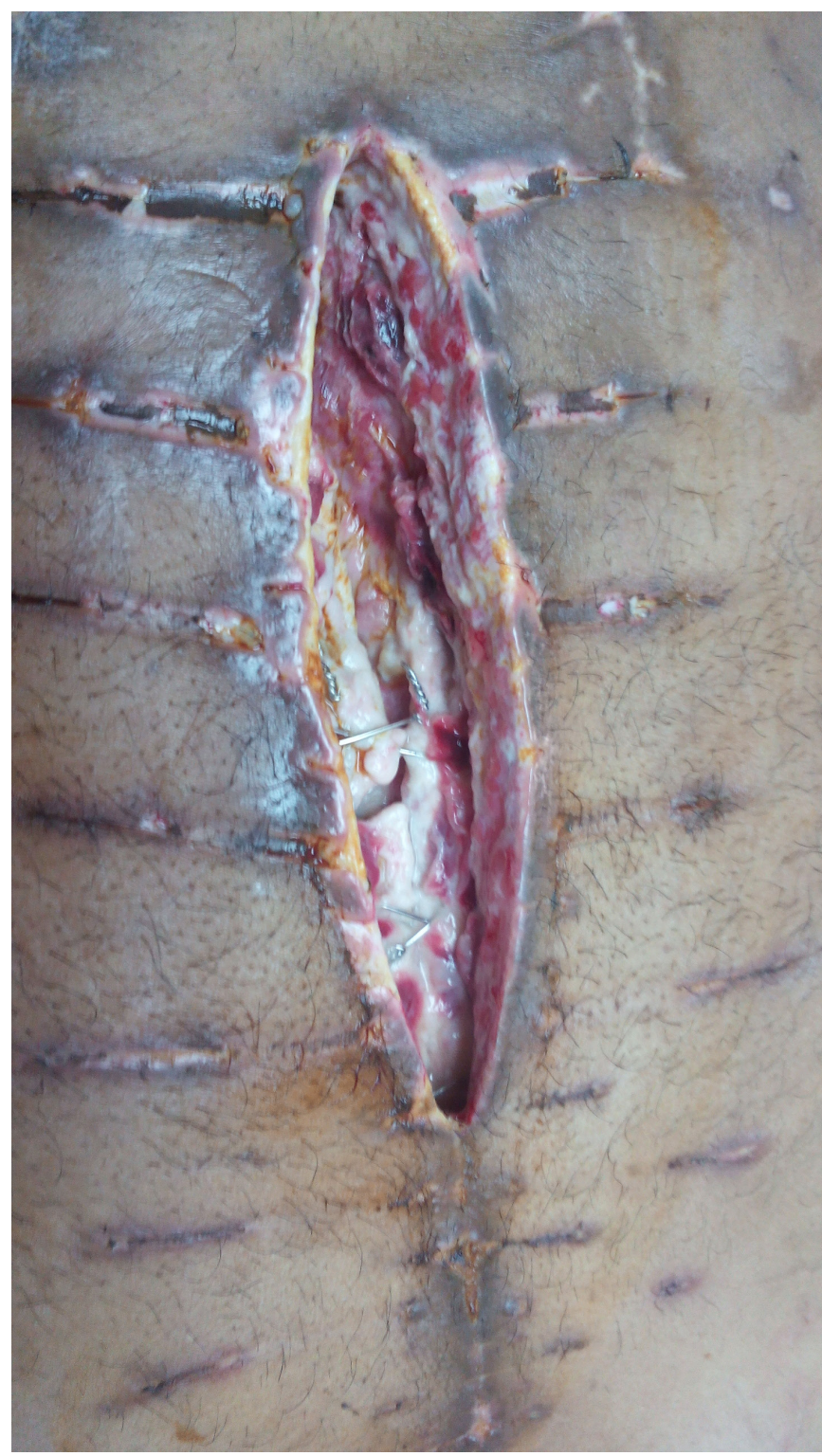

Figure 1. Complete sternal dehiscence and necrosis after second rewiring. 


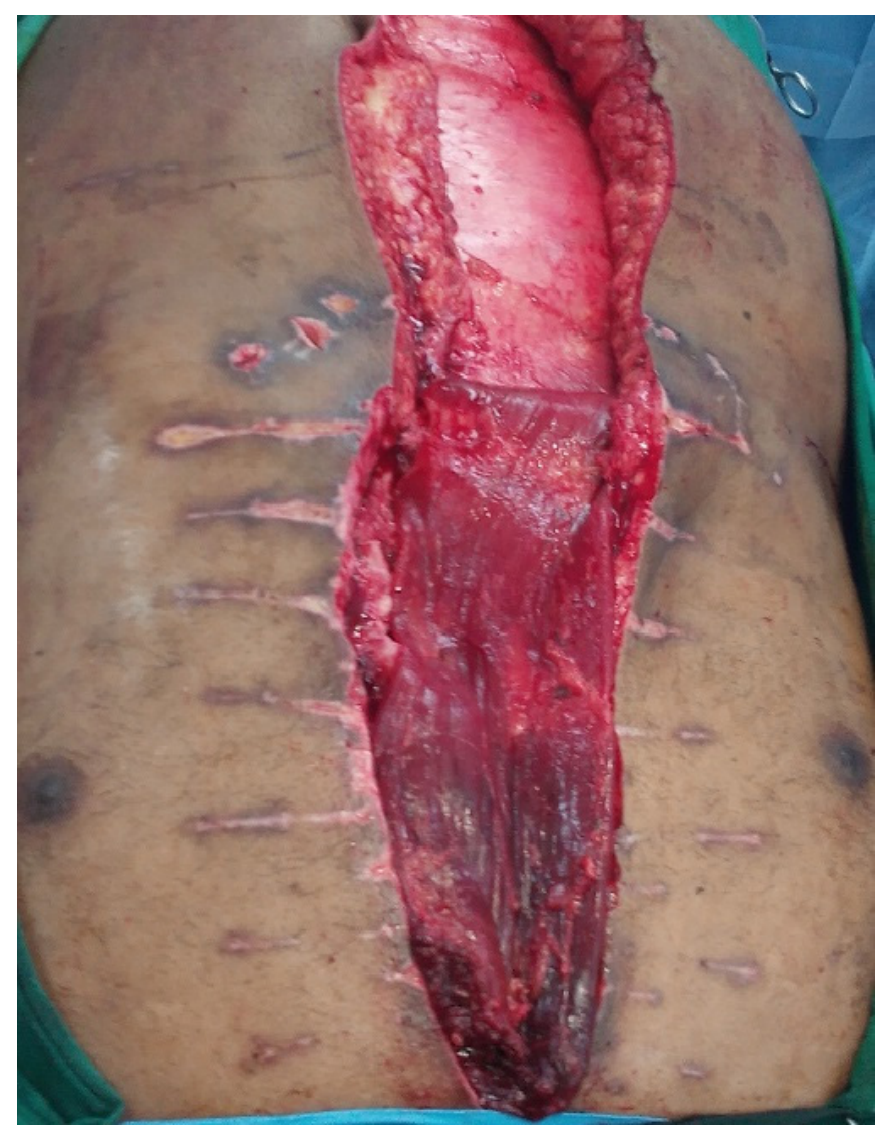

Figure 2. Rectus abdominis flap covering the whole sternum.

rectus abdominis flap reconstruction (Figure 2). The right rectus abdominis flap was selected because of its retained blood supply, as the patient underwent left internal mammary artery harvesting for coronary bypass. An incision was made along the rectus muscle and complete mobilization down to pubic bone. The muscle was divided at the pubic attachment and rotated $180^{\circ}$ to fill the sternal wound. The right superior epigastric artery was protected as the main blood supply. Polypropylene mesh was used to fill the rectus abdominis defect to prevent abdominal hernia. The sternal wound was covered with subcutaneous tissues and skin. The wound healed well, and the patient was discharged (Figure 3).

\section{DISCUSSION}

\section{Strategy for Prevention}

DSWI is the most preventable complication of cardiac surgery when risk factors are identified and preventive measures are undertaken. Risk factors for sternotomy wound complications include older age, increased body mass index, smoking, and presence of comorbidities such as low immunity, diabetes mellitus, irradiation, reoperation, and chronic lung or kidney disease. Long operation time and bilateral use of internal mammary arteries in obese and diabetic patients contribute to higher risk of complications. Postoperative factors include

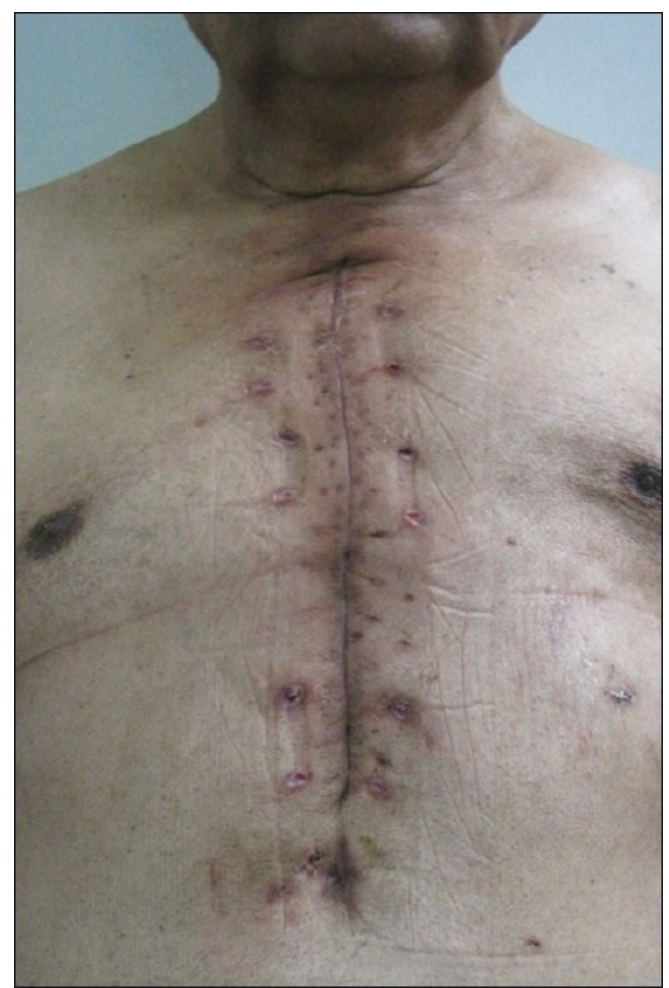

Figure 3. Healing after sternotomy wound complications.

prolonged ventilator support, inotropes, delayed chest closure, and tracheostomy [Schiraldi 2019; Lazar 2016].

The main preventive measures include preoperative control of blood glucose, meticulous disinfection, compliance with sterility principles, topical use of antimicrobials on the sternum, and prophylactic perioperative antibiotics [Lazar 2016]. Sternal stability is the most important factor in proper healing. Identification of high-risk cases preoperatively and application of the proper sternal closure technique are of crucial importance [Lazar 2016; Al Ebrahim 2003; Fawzy 2011] Table 1 summarizes the most important preventive measure for DSWI .

\section{STRATEGY FOR DIAGNOSIS AND MANAGEMENT}

The clinical diagnosis of purulent discharge is supported by laboratory identification of the organism and radiology findings. CT findings include dehiscence, fluid collection, wire displacement, and retrosternal collection [Zahiri 2012; Salehi Omran 2007]. Coagulase-negative Staphylococci/S. aureus are the most common pathogens. When infection persists after surgical and antibiotic treatments, Gram-negative rods, especially Enterobacteriaceae, are found more often [Lazar 2016; Salehi Omran 2007].

The 2 most important points to be dealt with in treatment of DSWI are sternal instability and degree of infection. Proper antibiotics based on sensitivity for $\geq 6$ weeks and adequate debridement are essential [Sears 2016; Weinand 2013]. 
Rule of 10: Summary of the 10 Most Important Preventive Measures for DSWI

\footnotetext{
Preoperative bathing with chlorhexidine; intranasal mupirocin

$1 \quad$ within $24 \mathrm{~h}$ of surgery, continued for 5 days in all patients with positive staphylococcal nasal swab

2 Correction of hypoalbuminemia and poor nutrition

3 Treatment of all extrathoracic infections before cardiac surgery

4 Preoperative glycemic control with insulin sliding scale

5 Smoking cessation and pulmonary function optimization

Preoperative cephalosporin $1 \mathrm{~h}$ before the skin incision, repeated for procedures lasting $>4 \mathrm{~h}$ and continued for $48 \mathrm{~h}$ postoperatively

Intraoperative continuous insulin infusion to maintain serum glucose level $<6 \mathrm{mmol}$

Topical antibiotics (vancomycin or gentamicin) applied to the cut edges of the sternum upon opening and before closing; vancomycin paste for bone marrow should replace bone wax

Midline sternotomy, optimum hemostasis, figure-8 closure technique, and in multiple fractures, the Robicsek technique

10

Early extubation and removal of drains and urinary and central venous catheters
}

NPWT, also known as vacuum-assisted closure (VAC), has been widely used in treatment as the best debridement healing promoter of various acute and chronic wounds [Debreneci 2008; Malmsjo 2009; Berdajs 2011]. The filling dressing used in NPWT includes silver foam dressing filling the wound gap and exposed to $-125-\mathrm{mmHg}$ negative pressure. Direct contact with the heart and great vessels must be avoided, as suction may cause exsanguination. In mediastinitis, bulky plain gauze interposition between the silver foam and the heart is recommended. The mechanisms for NPWT to promote wound healing include debridement, control of edema, decrease of exudate, decrease of local bacteria, improvement of local blood supply, and promotion of granulation tissue growth [Berdajs 2011].

Several surgical options exist in current practice, and there is a lack of consensus on optimal surgical management and when reconstructive flaps are needed [Davison 2007]. The amount of bone loss and the feasibility to approximate wound edges after debridement are the 2 most important factors in decision making regarding use of reconstructive flaps or primary closure. If the wound is clean and approximation is possible, direct sternal closure, either standard or reinforced, is the ideal solution. The most devastating picture of dehiscence is mediastinitis and complete sternal osteomyelitis. Plastic coverage is needed after adequate debridement. The sternotomy wound is divided vertically into upper and lower parts according to the inferior insertion of the pectoralis major muscle [Abu-Omar 2017]. In major upper sternal defects ( $>50 \%$ bone loss), pectoralis major as the muscle of choice can be mobilized on both sides or freed from the humeral attachment to cover the gap. In lower or whole sternal major gaps, pedicled rectus abdominis, latissimus dorsi, or greater omentum can be used to fill the space [Tewarie 2019; Yusuf 2018; Botianu 2019]. Epigastric herniation, bleeding, necrosis, and contamination of the peritoneal cavity are serious complications of omental flaps [Botianu 2019]. Pedicle rectus abdominis blood supply has to be secured; usually the right one is harvested when the left internal mammary artery has been used. Greater omentum or latissimus major is preferred when bilateral mammaries arteries have been used.

\section{CONCLUSION}

The combination of negative pressure treatment and rectus abdominis flap could effectively control wound infection and accelerate wound healing in cases of extensive mediastinitis and osteomyelitis. Multicenter, randomized trials and meta-analyses are needed to classify these wounds and recommend the best surgical strategy. A multidisciplinary team consisting of cardiothoracic surgeons, plastic surgeons, infectious disease specialists, radiologists, and clinical microbiologists is needed for proper management of complicated deep sternal infection.

\section{ACKNOWLEDGEMENTS}

This work was funded by the Deanship of Scientific Research (DSR), King Abdulaziz University, Jeddah, under grant no. D1441-523-140. The author acknowledges with thanks DSR technical and financial support.

\section{REFERENCES}

Abu-Omar Y, Kocher GJ, Bosco P, et al. 2017. European association for cardio-thoracic surgery expert consensus statement on the prevention and management of mediastinitis. Eur J Cardiothorac Surg 51:10-29.

Al Ebrahim K. 2003. Reinforced sternal closure: The bilateral straight longitudinal wire technique. Asian Cardiovasc Thorac Ann 11:90-91.

Berdajs DA, Trampuz A, Ferrari E, Ruchat P, Hurni M, von Segesser LK. 2011. Delayed primary versus late secondary wound closure in the treatment of postsurgical sternum osteomyelitis. Interact Cardiovasc Thorac Surg 12:914-918.

Botianu PVH. 2019. Current indications for the intrathoracic transposition of the omentum. J Cardiothorac Surg 14:103.

Cutrell JB, Barros N, McBroom M, et al. 2016. Risk factors for deep sternal wound infection after cardiac surgery: Influence of red blood cell transfusions and chronic infection. Am J Infect Control 44:1302-1309.

Davison SP, Clemens MW, Armstrong D, Newton ED, Swartz W. 2007. Sternotomy wounds: Rectus flap versus modified pectoral reconstruction. Plast Reconstr Surg 120:929-934.

Debreneci T, Szerafin T, Galajda Z, Miskolczi S, Peterfly A. 2008. Results of vauum-assisted wound closure system in the treatment of sternotomy wound infections following cardiac surgery. Magyar Sebeszet 61:10.1556.

Elassal A, Al-Ebrahim KE, Al-Radi O, Jabbad H, Eldib O. 2020. Sternal wound complications: Objective reclassification and surgical reconsideration. Heart Surg Forum 23:E076-E080. 
Farsky PS, Graner H, Duccini P, et al. 2011. Risk factors for sternal wound infections and application of the STS score in coronary artery bypass graft surgery. Rev Bras Cir Cardiovasc 26:624-629.

Fawzy H, Osei-Tutu K, Errett L, et al. 2011. Sternal plate fixation for sternal wound reconstruction: Initial experience (retrospective study). J Cardiothorac Surg 6:63.

Lazar HL, Salm TV, Engelman R, Orgill D, Gordon S. 2016. Prevention and management of sternal wound infections. Thorac Cardiovasc Surg 152:962-972.

Malmsjo M, Ingemansson R, Matrin R, Huddleston E. 2009. Negativepressure wound therapy using gauze or open-cell polyurethane foam: Similar early effects on pressure transduction and tissue contraction in an experimental porcine wound model. Wound Repair Rege 17:200-205.

Salehi Omran A, Karimi A, Ahmadi SH, et al. 2007. Superficial and deep sternal wound infection after more than 9000 coronary artery bypass graft (CABG): Incidence, risk factors and mortality. BMC Infect Dis 7:112.

Schiraldi L, Jabbour G, Centofanti P, et al. 2019. Deep sternal wound infections: Evidence for prevention, treatment, and reconstructive surgery. Arch Plast Surg 46:291-302.

Sears ED, Wu L, Waljee JF, Momoh AO, Zhong L, Chung KC. 2016. The impact of deep sternal wound infection on mortality and resource utilization: A population-based study. World J Surg 40:2673-2680.

Tewarie L, Moza AK, Khattab MA, Autschbach R, Zayat R. 2019. Effective combination of different surgical strategies for deep sternal wound infection and mediastinitis. Ann Thorac Cardiovasc Surg 25:102-110.

Weinand C, Phan TQV, Perbix W, et al. 2013. A reconstructive algorithm for deep sternal wound coverage: The Cologne-Merheim approach. Eur J Plast Surg 36:95-104.

Yusuf E, Chan M, Renz N, Tranpuz A. 2018. Current perspectives on diagnosis and management of sternal wound infections. Infect Drug Resist 11:961-968.

Zahiri HR, Lumpkins K, Kelishadi SS, et al. 2012. Significant predictors of complications after sternal wound reconstruction: A 21-year experience. Ann Plast Surg 69:439-441. 